\title{
PERILAKU BALOK KAYU MERANTI SEBAGAI BAHAN BANGUNAN UTAMA RUMAH TRADISIONAL ACEH
}

\author{
Helwiyah Zain ${ }^{1}$ \\ ${ }^{1)}$ Program Studi Teknik Sipil, Fakultas Teknik, Universitas Abulyatama \\ Jl. Blang Bintang Lama Km 8,5 Lampoh Keude Aceh Besar, \\ email: ocudma2h@gmail.com
}

\begin{abstract}
The objective of this research is to get the behaviour of Meranti wood beams as a material of Aceh traditional building. The behaviour is to gain the relationship between loaddeflection of wood beams test. Meranti woods are got from 6 locations of woods machinery i.e: 3 locations in the area Banda Aceh and other 3 lcations in Aceh Besar. The flexural test was used $5 \times 7 \times 120 \mathrm{~cm}$ wood beams size, and total 30 specimens.from those 6 locations. To get other supporting data, the other test was done i.e.: physical characteristic and mechanical characteristic. Physical characteristic was done with specific gravity test, and moisture content test which are 10 specimens each test. Mechanical characteristic was done with tensile test and compression test which are 10 specimens each test. The result of the test obtained moisture content was $13,19 \%$ at $28,9^{\circ}$ C temperature. Average specific gravity was 0,429. Tensile strength parallel to main fiber was $448,1 \mathrm{~kg} / \mathrm{cm} 2$ at $0,53 \%$ average maximum strain. Compression strength parallel to main fiber was $316,9 \mathrm{~kg} / \mathrm{cm}^{2}$ at $0,41 \%$ average maximum strain. Average modulus of elasticity from tensile test was found $84.547 \mathrm{~kg} / \mathrm{cm}^{2}$. Flexural characteristic was a relationship between load-deflection plotted as a graph in the text. Based on these result could be concluded that Meranti woods was appropriated to be material building Aceh traditional houses.
\end{abstract}

Key words: physical characteristics, mechanical characteristics, moisture contents, specific gravity, tensile strength, compression strength, relationship load-deflections, graph.

\begin{abstract}
Abstrak : Penelitian ini bertujuan untuk mendapatkan gambaran perilaku balok kayu Meranti sebagai bahan bangunan utama rumah tradisional Aceh. Perilaku tersebut berupa hubungan beban-lendutan melalui pengujian lentur balok. Kayu Meranti diambil dari 6 lokasi kilang pengolahan kayu yaitu 3 lokasi di wilayah Kota Banda Aceh dan 3 lokasi di Kabupaten Aceh Besar. Pengujian lentur dilakukan terhadap 30 buah benda uji ukuran $5 \times 7 \times 120 \mathrm{~cm}$ masingmasing sebanyak 5 buah tiap lokasi. Di samping itu juga dilakukan pengujian untuk memperoleh data pendukung yaitu pengujian sifat-sifat fisis dan sifat mekanis. Pengujian sifat fisis yang dilakukan yaitu: pemeriksaan kadar lengas, dan pemeriksaan berat jenis masingmasing 10 buah benda uji. Pengujian sifat mekanis yang dilakukan adalah pengujian tarik sejajar serat dan pengujian tekan sejajar serat masing-masing 10 buah benda uji. Hasil penelitian diperoleh kadar lengas sebesar $13,19 \%$ pada temperatur rata-rata $28,9^{\circ} \mathrm{C}$. Berat jenis kayu rata-rata adalah 0,429 . Kuat tarik sejajar serat rata-rata sebesar $448,1 \mathrm{~kg} / \mathrm{cm}^{2}$ pada regangan maksimum rata-rata $0,53 \%$, dan kuat tekan rata-rata $316,9 \mathrm{~kg} / \mathrm{cm} 2$ pada regangan maksimum $0,41 \%$. Modulus elastisitas rata-rata berdasarkan pengujian tarik adalah 84.547 $\mathrm{kg} / \mathrm{cm}^{2}$. Sifat lentur balok kayu Meranti berupa hubungan beban-lendutan digambar dalam bentuk grafik. Berdasarkan hasil tersebut dapat disimpulkan bahwa Kayu Meranti ini cocok untuk dijadikan bahan bangunan utama rumah tradisional Aceh.
\end{abstract}

Kata kunci: sifat fisis, sifat mekanis, kadar lengas, berat jenis, kuat tarik, kuat tekan, hubungan beban-lendutan, grafik. 
Negara Indonesia terdiri dari daratan tinggi yang cukup luas, ditumbuhi kayu yang sangat berguna untuk bahan bangunan. Bahan bangunan yang menggunakan kayu antara lain adalah untuk bangunan rumah traisional, perancah, jembatan darurat dan lain-lain. Salah satu bangunan rumah tradisional adalah rumah Aceh yang digunakan masyarakat sebagai tempat tinggal sejak zaman penjajahan hingga saat ini. Rumah Aceh terdiri dari struktur rangka, dinding dan atap yang semuanya menggunakan bahan dari kayu.

Struktur bangunan rumah Aceh cukup stabil dan kuat, terutama terhadap goyangan seperti gempa dan angin. Kekuatan ini terbukti pada saat terjadi gempa dahsyat 9,2 Skala Richter pada tahun 2004, rumah Aceh tetap survive dan tidak ada yang rusak. Hal yang mendasari kekuatan dan kestabilan rumah Aceh ini terletak pada sambungan (joint) antara tiang dan gelagar, yang bersifat semi jepit. Sambungan ini dapat menyerap energi pada waktu terjadi goncangan.

Kayu yang tumbuh di hutan dalam wilayah daerah Aceh terdiri atas berbagai macam jenisnya, salah satu di antaranya adalah jenis kayu Meranti. Kayu ini banyak dipakai oleh masyarakat Aceh yang digunakan untuk berbagai macam keperluan seperti: rangka cetakan beton cor, gelagar jembatan darurat, rangka bangunan (lagur melintang, lagur memanjang dan tiang) rumah tradisional Aceh. Untuk mengetahui kekuatan kayu ini dalam menahan beban, maka perlu dilakukan penelitian terhadap perilaku bahan tersebut.
Penelitian dilakukan terhadap bahan kayu Meranti berupa pengujian terhadap kekuatan lentur dan kuat tarik sejajar serat. Untuk mendukung percobaan ini dilakukan beberapa percobaan pendukung seperti sifat fisis dan sifat mekanis.

Tujuan dari penelitian ini adalah untuk melihat perilaku balok kayu Meranti yang ada di wilayah Kota Banda Aceh dan wilayah Kabupaten Aceh Besar dapat digunakan sebagai bahan utama bangunan rumah tradisional Aceh. Dari hasil penelitian ini dapat diketahui kekuatan kayu Meranti dan perilaku lentur berupa hubungan bebanlendutan dari kayu tersebut.

\section{TINJAUAN PUSTAKA}

\section{Pemeriksaan kadar lengas}

Peralatan yang digunakan adalah oven dan timbangan. Benda uji ditimbang dan dimasukkan ke dalam oven pada temperatur $103+2^{\circ} \mathrm{C}$. Setiap selang waktu 3 jam benda uji ditimbang dan dicatat. Pekerjaan ini diulang-ulang pada setiap waktu 3 jam berikutnya sampai diperoleh berat benda uji tetap. Kadar lengas dihitung dengan persamaan 1.

$$
\mathrm{wc}=\frac{w i-w k o}{w k o} \times 100 \%
$$

$$
\begin{aligned}
\text { di mana : } & \\
\text { wc } & =\text { kadar lengas }(\%) \\
\text { wi } & =\text { berat kayu semula (gram) } \\
\text { wko } & =\text { berat kayu kering oven (gram) }
\end{aligned}
$$




\section{Pemeriksaan berat jenis kayu}

Peralatan yang digunakan adalah oven dan timbangan. Benda uji diukur panjang, lebar, dan tingginya kemudian ditimbang.

Perhitungan berat jenis selanjutnya dihitung dengan persamaan 2 .

$$
\mathrm{Sg}=\frac{w i}{\left[1+\left(\frac{M}{100}\right)\right] x L x b x t}
$$

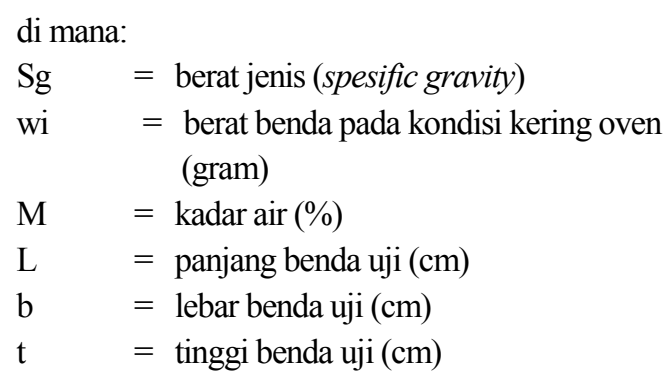

\section{Pengujian kuat tarik kayu}

Peralatan yang digunakan adalah mesin uji tarik dilengkapi dengan alat ukur beban dan regangan. Pencatatan yang dilakukan adalah besarnya beban dan regangan, pada tahap-tahap yang sudah ditentukan hingga benda uji putus. Kuat tarik diperoleh pada saat tegangan maksimum yang dihitung dengan persamaan 3 .

$$
\sigma=\frac{P}{F}
$$

$$
\begin{aligned}
\text { di mana } & : \\
\sigma & =\text { tegangan tarik maksimum }(\mathrm{kg} / \mathrm{cm} 2) \\
\mathrm{P} & =\text { beban tarik maksimum }(\mathrm{kg}) \\
\mathrm{F} & =\text { luas penampang benda uji }(\mathrm{cm} 2)
\end{aligned}
$$

\section{Pengujian kuat tekan}

Peralatan yang digunakan adalah mesin uji tekan dilengkapi dengan alat ukur beban dan regangan. Pencatatan yang dilakukan adalah besarnya beban dan regangan hingga benda uji hancur. Kuat tekan diperoleh pada keadaan tegangan maksimum yang dihitung juga dengan persamaan 3 .

\section{METODE PENELITIAN}

Metode penelitian yang diuraikan di sini adalah : material (bahan kayu), bentuk dan jumlah benda uji, pemeriksaan sifat-sifat fisis (kadar lengas dan berat jenis kayu), pemeriksaan sifat-sifat mekanis (pengujian tarik sejajar serat, pengujian tekan sejajar serat dan pengujian lentur).

\section{Sumber Material}

Material untuk penelitian ini adalah bahan kayu Meranti dibuat dalam beberapa jenis percobaan yaitu: pemeriksaan kadar lengas, pemeriksaan berat jenis, pengujian kuat tarik sejajar serat, pengujian kuat tekan sejajar serat dan pengujian lentur balok. Sumber material untuk penelitian ini diambil dari 6 buah lokasi panglong kayu yaitu: 3 lokasi di wilayah Kota Banda Aceh dan 3 lokasi di wilayah Kabupaten Aceh Besar.

\section{Jumlah Benda uji}

Benda uji yang digunakan pada penelitian ini bentuk dan jumlahnya disesuaikan dengan tujuan pengujian masingmasing yaitu: 1) pemeriksaan kadar lengas, 2) pemeriksaan berat jenis kayu, 3) pengujian kuta tarik, 4) pengujian kuat tekan dan 5) pengujian kuat lentur. Jumlah masingmasing benda uji seperti terlihat pada Tabel 1 . 
Tabel 1. Jumlah Benda Uji

\begin{tabular}{|c|c|c|}
\hline No & Tujuan pengujian & Jumlah \\
\hline 1 & Kadar Lengas & 10 \\
\hline 2 & Berat Jenis & 10 \\
\hline 3 & Kuat Tarik & 10 \\
\hline 4 & Kuat Tekan & 10 \\
\hline 5 & Kuat Lentur & 30 \\
\hline
\end{tabular}

\section{Bentuk dan Ukuran Benda Uji}

Bentuk dan ukuran benda uji disesuaikan dengan tujuan pengujian berdasarkan Anonim (1979), adalah sebagai berikut:

\section{(1) Benda uji kadar lengas dan berat jenis}

Bentuk benda uji kadar lengas dan berat jenis diperlihatkan pada Gambar 1.

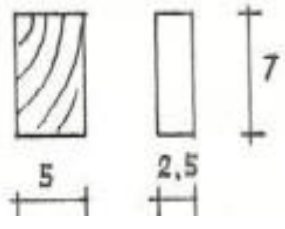

Gambar 1. Benda Uji kadar lengas dan berat jenis

\section{(2) Benda uji kuat tarik}

Bentuk benda uji untuk pengujian kekuatan tarik diperlihatkan pada

Gambar 2.

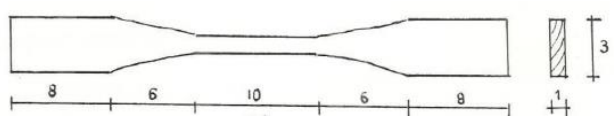

Gambar 2. Benda uji pengujian tarik

\section{(3) Benda uji kuat tekan}

Bentuk benda uji untuk pengujian kekuatan tekan diperlihatkan pada Gambar 3.

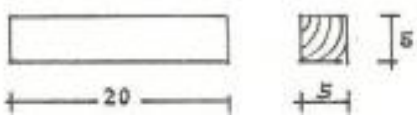

Gambar 3. Benda uji pengujian tekan

\section{(4) Benda uji kuat lentur}

Bentuk benda uji untuk pengujian kekuatan lentur ukuran 5x7x120 cm, diperlihatkan pada Gambar 4.

Gambar 4. Benda uji pengujian lentur

Peralatan yang digunakan adalah mesin uji lentur dilengkapi dengan alat ukur beban dan lendutan. Beban yang bekerja pada balok berupa beban terpusat sebanyak dua buah yang posisinya simetris terhadap panjang balok, seperti terlihat pada Gambar 5.

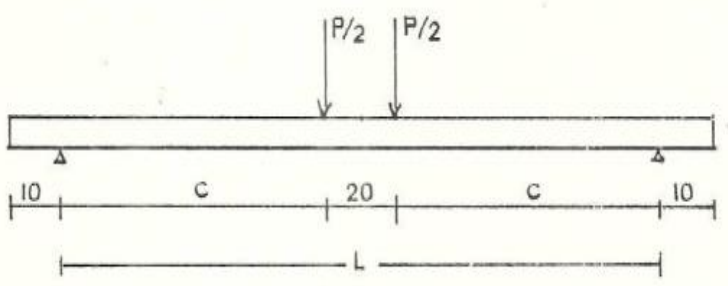

Gambar 5. Letak beban pada benda uji lentur

Pemberian dua buah beban terpusat dimaksudkan agar pada daerah yang ditinjau (jarak antara beban) tidak timbul tegangan geser.

Data yang dicatat selama pengujian adalah data beban dan data lendutan. Hal ini dilakukan tahap demi tahap sampai benda uji hancur (patah). Pola kehancuran balok digambar untuk dijadikan sebagai bahan pembahasan. 


\section{HASIL DAN PEMBAHASAN}

Berdasarkan pengujian terhada semua benda uji, berikut ini disajikan hasil pengujian yaitu: kadar lengas kayu, berat jenis kayu, kuat tarik kayu, kuat tekan dan perilaku lentur balok.

\section{Kadar Lengas}

Hasil pemeriksaan kadar lengas seperti terlihat pada Tabel 2. Berdasarkan hasil pemeriksaan kadar lengas, diperoleh kadar lengas 13,19 termasuk dalam jenis kayu kelas kuat III mutu A, seperti diusulkan oleh Dumanauw (2003), yaitu (12\%-18\%).

\section{Berat Jenis}

Hasil pemeriksaan berat jenis kayu seperti terlihat pada Tabel 3. Berdasarkan hasil pemeriksaan berat jenis, diperoleh berat jenis kayu 0,429 termasuk dalam jenis kayu kelas kuat III seperti diusulkan oleh Dumanauw (2003), yaitu $(0,4-0,6)$.

Tabel 2. Hasil pemeriksaan kadar lengas

\begin{tabular}{|c|c|c|c|c|c|}
\hline \multirow{2}{*}{$\begin{array}{l}\text { No. } \\
\text { Urt. }\end{array}$} & \multirow{2}{*}{$\begin{array}{c}\text { Nomor } \\
\text { Benda } \\
\text { Uji }\end{array}$} & \multicolumn{2}{|c|}{ Berat Benda Uji (gr) } & \multirow{2}{*}{$\begin{array}{c}\text { Kadar } \\
\text { Lengas } \\
(\%)\end{array}$} & \multirow{2}{*}{$\begin{array}{c}\text { Temp. } \\
\text { Ruang } \\
(\mathrm{oC})\end{array}$} \\
\hline & & $\begin{array}{l}\text { Kering } \\
\text { Udara }\end{array}$ & $\begin{array}{c}\text { Kering } \\
\text { Oven }\end{array}$ & & \\
\hline 1 & KL-1 & 46,22 & 40,88 & 13,06262 & 29 \\
\hline 2 & KL-2 & 43,57 & 38,36 & 13,58186 & 29 \\
\hline 3 & KL-3 & 44,58 & 39,42 & 13,0898 & 28 \\
\hline 4 & KL-4 & 49,27 & 44,09 & 11,7487 & 28 \\
\hline 5 & KL-5 & 45,33 & 40,82 & 11,04851 & 28 \\
\hline 6 & KL-6 & 44,59 & 39,21 & 13,72099 & 29 \\
\hline 7 & KL-7 & 45,25 & 40,14 & 12,73044 & 29 \\
\hline 8 & KL-8 & 46,16 & 40,68 & 13,47099 & 29 \\
\hline 9 & KL-9 & 42,77 & 37,89 & 12,87939 & 30 \\
\hline 10 & KL10 & 45,79 & 39,28 & 16,57332 & 30 \\
\hline \multicolumn{4}{|c|}{ Nilai rata-rata } & 13,19066 & 28,9 \\
\hline
\end{tabular}

Tabel 3. Hasil pemeriksaan berat jenis

\begin{tabular}{|c|c|c|c|c|c|c|c|c|}
\hline \multirow{2}{*}{$\begin{array}{l}\text { No. } \\
\text { Urt }\end{array}$} & \multirow{2}{*}{$\begin{array}{c}\text { Nomor } \\
\text { Benda } \\
\text { Uji }\end{array}$} & \multirow{2}{*}{$\begin{array}{l}\text { Berat } \\
\text { Kering } \\
\text { Oven }\end{array}$} & \multicolumn{3}{|c|}{ Ukuran Benda Uji } & \multirow{2}{*}{$\begin{array}{c}\text { Volume } \\
\text { Benda } \\
\text { Uji }\end{array}$} & \multirow{2}{*}{$\begin{array}{c}\text { Kadar } \\
\text { Air } \\
(\%)\end{array}$} & \multirow{2}{*}{$\begin{array}{l}\text { Berat } \\
\text { Jenis }\end{array}$} \\
\hline & & & $\begin{array}{c}\text { Panjang } \\
(\mathrm{cm})\end{array}$ & $\begin{array}{c}\text { Lebar } \\
(\mathrm{cm})\end{array}$ & $\begin{array}{l}\text { Tinggi } \\
(\mathrm{cm})\end{array}$ & & & \\
\hline 1 & $\mathrm{BJ}-1$ & 43,21 & 2,37 & 5,02 & 6,97 & 82,92488 & 14,82 & 0,453818 \\
\hline 2 & BJ-2 & 42,84 & 2,32 & 5,01 & 7,01 & 81,47863 & 15,97 & 0,453378 \\
\hline 3 & BJ-3 & 43,53 & 2,68 & 4,98 & 6,77 & 90,35513 & 15,75 & 0,416212 \\
\hline 4 & BJ-4 & 43,25 & 2,57 & 5,04 & 6,98 & 90,41054 & 15,22 & 0,415183 \\
\hline 5 & BJ-5 & 44,13 & 2,62 & 5,02 & 7,03 & 92,46137 & 16,58 & 0,409402 \\
\hline 6 & BJ-6 & 43,19 & 2,44 & 5,01 & 6,89 & 84,22612 & 14,28 & 0,44871 \\
\hline 7 & BJ-7 & 42,47 & 2,66 & 4,98 & 7,01 & 92,86007 & 17,83 & 0,388148 \\
\hline 8 & BJ-8 & 43,22 & 2,68 & 4,97 & 6,98 & 92,97081 & 16,58 & 0,398762 \\
\hline 9 & BJ-9 & 44,22 & 2,29 & 5,01 & 7,03 & 80,65449 & 16,84 & 0,469244 \\
\hline 10 & BJ-10 & 43,85 & 2,43 & 5,02 & 6,99 & 85,26821 & 15,37 & 0,445748 \\
\hline \multicolumn{8}{|c|}{ Nilai rata-rata } & 0,429861 \\
\hline
\end{tabular}




\section{Kuat Tarik Sejajar Serat}

Hasil percobaan kuat tarik kayu sejajar serat seperti terlihat pada Tabel.4.

Tabel 4. Hasil Pengujianan Kuat Tarik

\begin{tabular}{|c|c|c|c|c|}
\hline $\begin{array}{c}\text { No. } \\
\text { Urt. }\end{array}$ & $\begin{array}{c}\text { Nomor } \\
\text { Benda } \\
\text { Uji }\end{array}$ & $\begin{array}{c}\text { Luas } \\
\text { Penamp. } \\
(\mathrm{cm} 2)\end{array}$ & $\begin{array}{c}\text { Kuat } \\
\text { Tarik } \\
(\mathrm{kg} / \mathrm{cm} 2)\end{array}$ & $\begin{array}{c}\text { Regangan } \\
\text { maksimum } \\
(\%)\end{array}$ \\
\hline 1 & KTR-1 & 89,46 & 425 & 0,47 \\
\hline 2 & KTR-2 & 91,27 & 476 & 0,57 \\
\hline 3 & KTR-3 & 92,31 & 458 & 0,56 \\
\hline 4 & KTR-4 & 86,85 & 489 & 0,51 \\
\hline 5 & KTR-5 & 88,27 & 466 & 0,54 \\
\hline 6 & KTR-6 & 91,74 & 436 & 0,55 \\
\hline 7 & KTR-7 & 89,37 & 456 & 0,52 \\
\hline 8 & KTR-8 & 90,24 & 422 & 0,51 \\
\hline 9 & KTR-9 & 88,41 & 419 & 0,54 \\
\hline 10 & KTR- & 87,32 & 434 & 0,53 \\
\hline \multicolumn{5}{|l}{ Nilai rata-rata } \\
\end{tabular}

Berdasarkan hasil pengujian kuat tarik sejajar serat seperti pada Tabel 4 di atas, diperoleh kuat tarik kayu rata-rata 448,1 $\mathrm{kg} / \mathrm{cm}^{2}$ termasuk dalam jenis kayu kelas kuat III seperti diusulkan oleh Dumanauw (2003), yaitu $\left(500 \mathrm{~kg} / \mathrm{cm}^{2}-725 \mathrm{~kg} / \mathrm{cm}^{2}\right)$.

Modulus elastisitas kayu Meranti berdasarkan data hasil pengujian tarik sejajar serat adalah $84.547 \mathrm{~kg} / \mathrm{cm}^{2}$ termasuk dalam jenis kayu kelas kuat III seperti ditetapkan oleh Anonim (1961), yaitu $80.000 \mathrm{~kg} / \mathrm{cm}^{2}$.

\section{Kuat Tekan Sejajar Serat}

Hasil percobaan kuat tekan kayu sejajar serat seperti terlihat pada Tabel 5 . Berdasarkan hasil pengujian kuat tekan sejajar serat, diperoleh kuat tekan kayu ratarata $316,9 \mathrm{~kg} / \mathrm{cm}^{2}$, termasuk dalam jenis kayu kelas kuat III seperti diusulkan oleh Dumanauw (2003), yaitu $\left(300 \mathrm{~kg} / \mathrm{cm}^{2}-425\right.$ $\left.\mathrm{kg} / \mathrm{cm}^{2}\right)$.
Tabel 5. Hasil Pengujianan Kuat Tekan

\begin{tabular}{|c|c|c|c|c|}
\hline $\begin{array}{c}\text { No. } \\
\text { Urt }\end{array}$ & $\begin{array}{c}\text { Nomor } \\
\text { Benda } \\
\text { Uji }\end{array}$ & $\begin{array}{c}\text { Luas } \\
\text { Penamp } \\
(\mathrm{cm} 2)\end{array}$ & $\begin{array}{c}\text { Kuat } \\
\text { Tekan } \\
(\mathrm{kg} / \mathrm{cm} 2)\end{array}$ & $\begin{array}{c}\text { Regangan } \\
\text { maksimum } \\
(\%)\end{array}$ \\
\hline 1 & KTK-1 & 25 & 326 & 0,42 \\
\hline 2 & KTK-2 & 25 & 307 & 0,45 \\
\hline 3 & KTK-3 & 25 & 296 & 0,4 \\
\hline 4 & KTK-4 & 25 & 314 & 0,44 \\
\hline 5 & KTK-5 & 25 & 318 & 0,37 \\
\hline 6 & KTK-6 & 25 & 305 & 0,45 \\
\hline 7 & KTK-7 & 25 & 326 & 0,41 \\
\hline 8 & KTK-8 & 25 & 332 & 0,4 \\
\hline 9 & KTK-9 & 25 & 338 & 0,39 \\
\hline 10 & $\begin{array}{c}\text { KTK- } \\
10\end{array}$ & 25 & 307 & 0,37 \\
\hline \multicolumn{3}{|c|}{ Nilai rata-rata } & 316,9 & 0,41 \\
\hline
\end{tabular}

\section{Kuat Lentur Balok}

Hasil percobaan kuat lentur balok seperti terlihat pada Tabel 6. Pada Tabel 6, benda uji sebanyak 30 buah dikelompokkan ke dalam 5 kelompok. Masing-masing kelompok diambil nilai lendutan rata-rata. Kelima kelompok ini nilai akhir dirata-ratakan lagi sehingga diperoleh nilai lendutan untuk setiap besarnya beban. Hubungan beban-lendutan pada setiap tahap beban dapat digambar pada grafik seperti terlihat pada Gambar 6 .

\section{Diskusi}

Berdasarkan hasil pemeriksaan kadar lengas, berat jenis kayu, kuat tarik sejajar serat, kuat tekan sejajar serat, kuat lentur balok dan nilai modulus elastisitas, menunjukkan bahwa kayu Meranti yang diteliti tersebut termasuk dalam katagori kayu kelas kuat III. Dari segi kekuatan tarik dan kekuatan tekan nilainya tidak jauh berbeda, sehingga cocok digunakan pada konstruksi yang menahan beban bolak-balik seperti beban gempa. 
Tabel 6. Hasil Pengujian Kuat Lentur Balok

\begin{tabular}{|c|c|c|c|c|c|c|c|}
\hline No. & Beban & \multicolumn{7}{|c|}{ Lendutan rata-rata $(\mathrm{mm})$} \\
\cline { 3 - 7 } Urt. & $(\mathrm{kg})$ & $\begin{array}{c}\mathrm{BU} \\
1 \mathrm{~d} / \mathrm{s} 6\end{array}$ & $\begin{array}{c}\mathrm{BU} \\
7 \mathrm{~s} / \mathrm{d} 12\end{array}$ & $\begin{array}{c}\mathrm{BU} \\
13 \mathrm{~s} / \mathrm{d} 18\end{array}$ & $\begin{array}{c}\mathrm{BU} \\
19 \mathrm{~s} / \mathrm{d} 24\end{array}$ & $\begin{array}{c}\mathrm{BU} \\
25 \mathrm{~s} / \mathrm{d} 30\end{array}$ & Rata-rata \\
\hline 1 & 100 & 0,18 & 0,21 & 0,19 & 0,22 & 0,21 & 0,202 \\
\hline 2 & 200 & 0,36 & 0,41 & 0,37 & 0,42 & 0,38 & 0,388 \\
\hline 3 & 300 & 0,55 & 0,61 & 0,57 & 0,59 & 0,54 & 0,572 \\
\hline 4 & 400 & 0,94 & 0,99 & 0,92 & 1,02 & 0,96 & 0,966 \\
\hline 5 & 500 & 1,22 & 1,18 & 1,16 & 1,28 & 1,32 & 1,232 \\
\hline 6 & 600 & 1,56 & 1,68 & 1,59 & 1,63 & 1,61 & 1,614 \\
\hline 7 & 700 & 1,98 & 1,96 & 2,06 & 2,12 & 2,08 & 2,04 \\
\hline 8 & 800 & 2,48 & 2,62 & 2,58 & 2,52 & 2,59 & 2,558 \\
\hline 9 & 900 & 2,87 & 2,95 & 2,98 & 2,86 & 2,92 & 2,916 \\
\hline 10 & 1000 & 3,38 & 3,57 & 3,48 & 3,42 & 3,59 & 3,488 \\
\hline 11 & 1100 & 3,85 & 3,82 & 3,98 & 4,02 & 3,85 & 3,904 \\
\hline 12 & 1200 & 4,72 & 4,84 & 4,96 & 4,82 & 4,72 & 4,812 \\
\hline 13 & 1300 & 5,64 & 5,96 & 5,72 & 5,87 & 5,91 & 5,82 \\
\hline 14 & 1400 & 7,42 & 7,08 & 7,47 & 7,28 & 7,17 & 7,284 \\
\hline
\end{tabular}

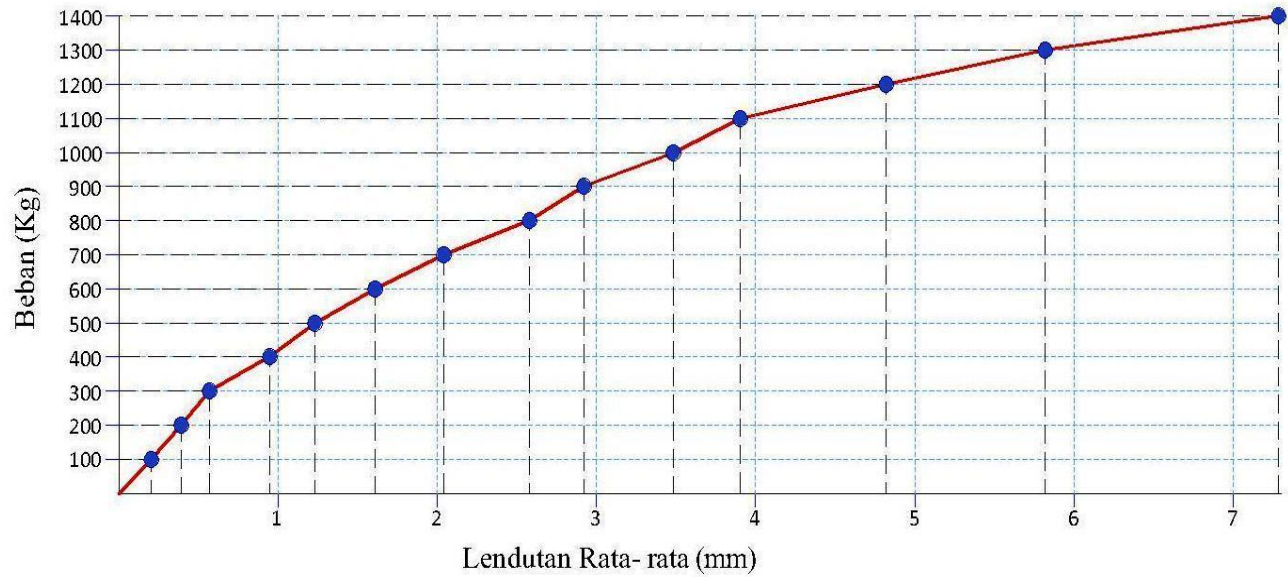

Gambar 6. Grafik hubungan beban-lendutan balok kayu Meranti

Kayu kelas kuat III dapat digunakan sebagai bahan struktur rangka bangunan konstruksi kayu untuk konstruksi bangunan utama rumah tradisional Aceh, karena beban yang bekerja pada lagur bangunan sederhana timbul tegangan lentur $<75 \mathrm{~kg} / \mathrm{cm}^{2}$. Selain itu kayu Meranti ini dapat juga digunakan untuk konstruksi: jembatan darurat, konstruksi perancah dan cetakan untuk pengecoran

Volume 1, No. 1, Januari 2015 beton, dan lain-lain.

Dari Gambar 6, terlihat bahwa hubungan beban-lendukan mendekati garis lurus, dengan demikian mempunyai sifat kayu pada umumnya.

\section{KESIMPULAN DAN SARAN}

Berdasarkan hasil pemeriksaan dan pengujian yang dilakukan pada penelitian ini, yaitu perilaku balok kayu Meranti sebagai 
bahan bangunan utama rumah tradisional Aceh, dapat diperoleh kesimpulan sebagai berikut:

1. Kadar lengas kayu diperoleh $13,19 \%$ pada temperatur rata-rata $28,9^{\circ} \mathrm{C}$. Berat jenis kayu rata-rata adalah 0,429 . Kuat tarik sejajar serat rata-rata sebesar 448,1 $\mathrm{kg} / \mathrm{cm}^{2}$ pada regangan maksimum ratarata $0,53 \%$, dan kuat tekan rata-rata $316,9 \mathrm{~kg} / \mathrm{cm} 2$ pada regangan maksimum 0,41\%. Modulus elastisitas rata-rata berdasarkan pengujian tarik adalah $84.547 \mathrm{~kg} / \mathrm{cm}^{2}$. Berdasarkan hasil tersebut, maka kayu Meranti ini termasuk dalam jenis kayu kelas kuat III.

2. Kekuatan kayu Meranti tersebut cocok untuk bangunan tradisional rumah Aceh yang sering dilanda gempa.

3. Tegangan yang timbul pada lagur bangunan tradisional rumah Aceh (termasuk katagori bangunan sederhana) tidak melebihi tegangan izin kayu kelas III, sehingga bahan kayu ini cukup kuat bila digunakan pada bangunan tradisional rumah Aceh.

4. Jika terjadi beban yang berlebihan sampai dengan 50\%, maka konstruksi bangunan tradisional rumah Aceh masih aman.

\section{DAFTAR PUSTAKA}

Anonim, American Society for Testing and Material, 1979.

Anonim, Peraturan Konstruksi Kayu Indonesia, NI-5, 1961, Departemen
Pekerjaan Umum dan Tenaga

Listrik, Direktorat Jenderal Cipta

Karya. Lembaga Penyelidikan

Masalah Bangunan.

Wirjornartono. S., Konstruksi Kayu, KMTS-UGM, Yogyakarta, 1977.

Supranto. J., Statistik Teori dan Aplikasi, edisi kelima penerbit ErlanggaJakarta, 1987.

Yap. K.H.F., Konstruksi Kayu, Dhiwantara, Jakarta, 1964.

Dumanauw, J., F., Mengenal Kayu, Kanisius, Semarang, 2003, 